\title{
Fair Plan 9: Engineering Human Population to Help Safeguard Earth's Climate
}

\author{
Michael E. Schlesinger \\ Department of Atmospheric Sciences, University of Illinois at Urbana-Champaign, Urbana, IL, USA \\ Email: schlesin@illinois.edu
}

Received 29 March 2016; accepted 26 April 2016; published 29 April 2016

Copyright (C) 2016 by author and Scientific Research Publishing Inc.

This work is licensed under the Creative Commons Attribution International License (CC BY). http://creativecommons.org/licenses/by/4.0/

(c) (i) Open Access

\begin{abstract}
Our Fair Plan to Safeguard Earth's Climate reduces the emission of greenhouse gases to zero over the 80-year time period 2020 to 2100 . To accomplish this, humanity must reduce its carbon intensity-the amount of $\mathrm{CO}_{2}$ emitted per unit of energy-and its energy intensity-the amount of energy needed to generate a unit of Gross World Product. As shown in our Fair Plan 8 paper, reducing the future growth of the human population can also contribute to the reduction in greenhouse-gas emissions. Here, we explore this further. We project the historical decrease in Total Fertility Rate (TFR) across the $21^{\text {st }}$ century toward its logistical asymptotic Reference value of 2.04 Births Per Woman (BPW). We then engineer the asymptotic TFR beginning in 2020 to 1.95, 1.85, $1.75,1.65 \& 1.55 \mathrm{BPW}$. We project the population across the $21^{\text {st }}$ century for the Reference and engineered TFRs. We do so using the results of Basten, Lutz and Scherbov (2013) for the population evolution across the $21^{\text {st }}$ century for 8 constant TFR values $(=2.50,2.25,2.00,1.75,1.50,1.25$, $1.00 \& 0.75 \mathrm{BPW}$ ). We find that purposefully engineering the asymptotic TFR can significantly contribute to achieving the reduction in greenhouse-gas emissions needed to transition to our Fair Plan to Safeguard Earth's Climate.
\end{abstract}

\section{Keywords}

Climate Change, Fair Plan, Population Engineering, Total Fertility Rate

\section{Introduction}

The emission rate of carbon dioxide $\left(\mathrm{CO}_{2}\right)$ gas into Earth's atmosphere by the burning of fossil fuels (coal, oil and natural gas) via human activity can be represented mathematically by the Kaya Identity [1] [2]:

$$
\dot{\mathrm{C}}=\mathrm{P} \cdot \mathrm{W} \cdot \mathrm{I}_{\mathrm{E}} \cdot \mathrm{I}_{\mathrm{C}} \text {, }
$$


where $\dot{C}$ is the emission rate of carbon dioxide in billions of metric tons of carbon per year (GtC/year), $P$ is the human population (billions of people),

$$
\mathrm{W}=\mathrm{GWP} / \mathrm{P},
$$

is the wealth per person, with GWP the Gross World Product (thousands of 1990 US dollars),

$$
\mathrm{I}_{\mathrm{E}}=\mathrm{E} / \mathrm{GWP},
$$

is the energy intensity $=$ the annual energy used (exajoules $=\mathrm{EJ}=10^{18}$ joules) per unit of GWP, and

$$
\mathrm{I}_{\mathrm{C}}=\dot{\mathrm{C}} / \mathrm{E}
$$

is the carbon intensity = the annual carbon dioxide emission per unit of energy.

As far as we know, all emission-abatement policies proposed heretofore, save one, have focused exclusively on reducing $\mathrm{I}_{\mathrm{C}}$ and $\mathrm{I}_{\mathrm{E}}$, the former by increasing energy efficiency and the latter by increasing decarbonization. It has been taboo even to consider reducing P. This taboo was reflected in the Encyclical Letter of Pope Francis, Laudato Si' (Praise Be to You): On Care for Our Common Home” [3], where, in Paragraph 50, it is written:

"Instead of resolving the problems of the poor and thinking of how the world can be different, some can only propose a reduction in the birth rate... Yet 'while it is true that an unequal distribution of the population and of available resources creates obstacles to development and a sustainable use of the environment, it must nonetheless be recognized that demographic growth is fully compatible with an integral and shared development'. To blame population growth instead of extreme and selective consumerism on the part of some, is one way of refusing to face the issues."

The single exception is our antecedent paper, “Fair Plan 8: Earth’s Climate Future - Pope Francis' Population Mistake" [4], wherein we showed that Population Matters. In particular, we showed that by reducing P of the high A2 end-member scenario of the SRES scenarios to the low B1 end-member scenario, keeping $\mathrm{W}, \mathrm{I}_{\mathrm{E}}$ and $\mathrm{I}_{\mathrm{C}}$ of the A2 scenario:

“... that in the modified A2 scenario, the carbon emission rate increases to about $13.5 \mathrm{GtC} /$ year in 2070 and thereafter remains quasi constant, ending the century at $12.9 \mathrm{GtC}$. This is $47 \%$ of [the] $27.6 \mathrm{GtC}$ emitted in 2100 in the unmodified A2 scenario. Consequently, POPULATION MATTERS!”

Here, we continue the exploration of the effect of reducing P on $\dot{\mathrm{C}}$. In particular, we will calculate the contribution to the reduction in $\dot{C}$ from our Reference emission scenario to the $\dot{C}$ required by our Fair Plan emission scenario achieved only by reducing $\mathrm{P}$ from our Reference Population scenario to our Engineered-Population scenario. In so doing, we will show the compliment thereto, that is, how much of the required reduction in $\dot{\mathrm{C}}$ from the Reference emission scenario to the Fair Plan emission scenario is required by reducing $\mathrm{I}_{\mathrm{E}}$ and $\mathrm{I}_{\mathrm{C}}$.

Before we embark on this endeavor, it is useful to set the historical background for our engineering the population to reduce the emission of $\mathrm{CO}_{2}$ and other human-caused greenhouse gases from the Reference emission scenario to the Fair Plan emission scenario. In this vein, Figure 1 presents the history of human population (P, red curve) and total fertility rate (TFR, blue curve) from 1943 to 2016 based on the United Nations data on population [5] and fertility [6], and on references [7] [8]. It can be seen that $\mathrm{P}$ has more than tripled during the author's lifetime, from 2.3 billion people (BP) in 1943 to 7.4 BP in 2016, while TFR halved from 5 Births Per Woman (BPW) to $2.5 \mathrm{BPW}$. How will this remarkable behavior of TFR and P evolve during the remainder of the $21^{\text {st }}$ century absent any population engineering? We explore this question in the following section.

\section{Historical and Projected Future Total Fertility Rates}

Figure 2 presents the United Nations' historical global TFR versus time in pentads from 1950-1955 through 2010-2015 (red dots) [6]. This historical TFR versus time from 1965-1970 to 2010-2015 is well represented by

$$
\operatorname{TFR}_{\text {Ref }}(\mathrm{Y})=4.4470-2.4064\{1-\exp [-(\mathrm{Y}-1972.5) / 22.694]\}, \quad\left(\mathrm{R}^{2}=0.98503\right)
$$

where $\mathrm{Y}$ is the year. This TFR, which we take to be our reference scenario having no population engineering, 


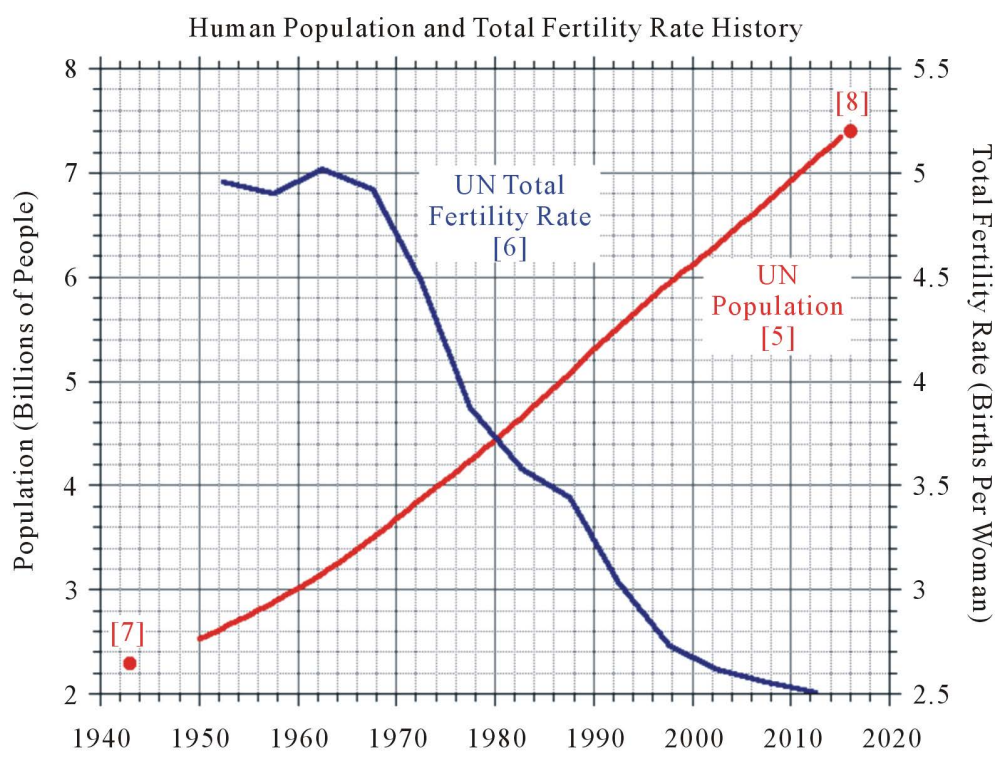

Figure 1. The history of human population (P, red curve) and total fertility rate (TFR, blue curve) from 1943 to 2016 based on the United Nations data on population [5] and fertility [6], and on references [7] [8].

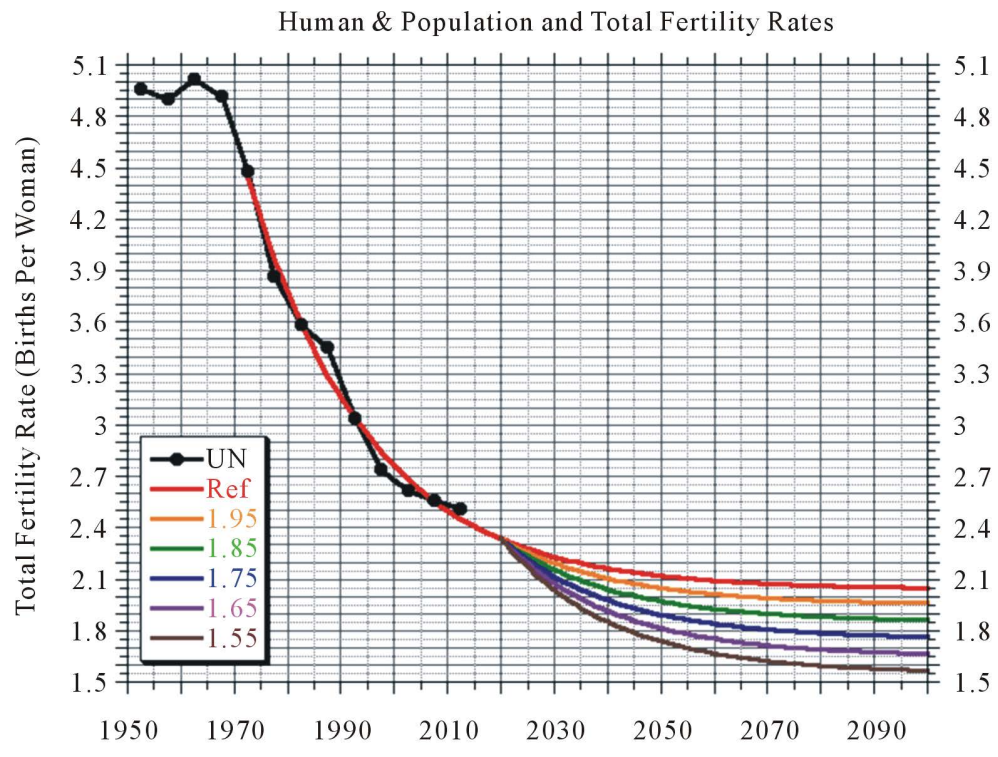

Figure 2. The United Nations' historical global TFR versus time in pentads from 1950-1955 through 2010-2015 (black dots and curve) [6], the fit thereof by Equation (5), red curve = our Reference scenario, and the TFR scenarios engineered by Equations (6); orange, green, blue, purple \& brown curves.

asymptotes to $4.4470-2.4064=2.0406 \mathrm{BPW}$, with TFR $(2100)=2.0493 \mathrm{BPW}$. We engineer the asymptotic TFR via

$$
\operatorname{TFR}_{j}(Y)=\operatorname{TFR}_{\text {Ref }}(Y)-D_{j}\{1-\exp [-(Y-2020) / 20]\}, j=1.95,1.85,1.75,1.65,1.55 \text {, }
$$

where

$$
D_{j}=0.0906+(1.95-j), j=1.95,1.85,1.75,1.65,1.55 .
$$

We have chosen the characteristic e-folding time of the engineered TFR evolution in Equation (6a) to be 20 
years. This is close to, but somewhat faster than, the 22.694-year e-folding time of the non-engineered TFR evolution in Equation (5).

\section{Population Model}

We construct our population model for years 2000 through 2100 from the results of Basten, Lutz and Scherbov (2013) [9; hereinafter BLS]. BLS calculated population from years 2000 through 2300 for 8 fixed values of TFR $(0.75,1.00,1.25,1.50,1.75,2.00,2.25 \& 2.50 \mathrm{BPW})$.

We represent their results by

$$
\mathrm{P}(\mathrm{y} ; \mathrm{TFR})=\mathrm{A}+\mathrm{B}[\mathrm{TFR}] \mathrm{y}+\mathrm{C}[\mathrm{TFR}] \mathrm{y}^{2}, \quad 0 \leq \mathrm{y} \leq 100,
$$

where $y$ is the year relative to 2000. We determine A, B[TFR] and C[TFR] from the results in Table S1 of BLS for P(0; TFR), P(50; TFR) and P(100; TFR) for a life expectancy of 90. (BLS' results for their other two life expectancies, 100 and 120 years, are negligibly different over the $21^{\text {st }}$ century from their results for 90 -year life expectancy.) These data are presented here in Table 1, together with the values of $A, B[T F R]$ and C[TFR]. We represent the TFR dependence of $\mathrm{B}[\mathrm{TFR}]$ and $\mathrm{C}[\mathrm{TFR}]$ by

$$
\begin{aligned}
& \mathrm{B}[\mathrm{TFR}]=0.052352+0.057248 \times \mathrm{TFR}-0.019505 \times \mathrm{TFR}^{2}, \quad 0.75 \leq \mathrm{TFR} \leq 2.50 \\
& \mathrm{C}[\mathrm{TFR}]=\left(-8.3055-6.6429 \times \mathrm{TFR}+4.2476 \times \mathrm{TFR}^{2}\right) \times 10^{-4}, \quad 0.75 \leq \mathrm{TFR} \leq 2.50
\end{aligned}
$$

Finally, we calculate the population in year $\mathrm{y}+1$ by

$$
\mathrm{P}(\mathrm{y}+1)=\mathrm{P}(\mathrm{y})+\alpha \Delta \mathrm{P}(\mathrm{y})+(1-\alpha) \Delta \mathrm{P}(\mathrm{y}+1), \mathrm{y}=0, \cdots, 99
$$

where

$$
\Delta \mathrm{P}(\mathrm{y})=\mathrm{B}[\operatorname{TFR}(\mathrm{y})]+2 \mathrm{C}[\operatorname{TFR}(\mathrm{y})] \cdot \mathrm{y}, \quad \mathrm{y}=0, \cdots, 100,
$$

The choice of interpolation factor $\alpha=0.5$ gives very nearly optimal results. The results from Equations (9) for constant TFR(y) $=0.75,1.00,1.25,1.50,1.75,2.00,2.25 \& 2.50$ BPW are presented in Figure 3 in comparison with the data of BLS shown in Table 1. It is seen that the agreement is satisfactory.

\section{Population Projection through the $21^{\text {st }}$ Century}

We use our population model, Equation (9), with initial condition $\mathrm{P}(0)=6.1266 \mathrm{BP}$, the UN observed value for year 2000 [5], to project the human population through the $21^{\text {st }}$ century for the 6 TFR curves of Figure 2, with TFR asymptotes $=2.04$ (Ref), 1.95. 1.85, 1.75, $1.65 \& 1.55$ BPW. Figure 4 shows that for the Reference TFR, the human population reaches 11.1 BP in 2100 when it is still increasing. This is very close to the UN median population projection in 2100 [10]. This is 5 times the size of the human population when the author was born in

Table 1. The population data of BLS for 2000, 2050 and 2100 versus TFR, together with the values of A, B[TFR] and C[TFR] for Equation (7).

\begin{tabular}{ccccccc}
\hline $\begin{array}{c}\text { TFR } \\
(\mathrm{BPW})\end{array}$ & $\begin{array}{c}\text { P(0; TFR }) \\
\text { (BP) }[9]\end{array}$ & $\begin{array}{c}\text { P(50; TFR) } \\
(\mathrm{BP})[9]\end{array}$ & $\begin{array}{c}\text { P(100; TFR }) \\
\text { (BP) }[9]\end{array}$ & A & B[TFR] & C[TFR] \\
\hline 0.75 & 6.05 & 7.54 & 3.52 & 6.05 & 0.0849 & $-1.102 \mathrm{E}-3$ \\
1.00 & 6.05 & 7.88 & 4.40 & 6.05 & 0.0897 & $-1.062 \mathrm{E}-3$ \\
1.25 & 6.05 & 8.23 & 5.49 & 6.05 & 0.0928 & $-9.840 \mathrm{E}-4$ \\
1.50 & 6.05 & 8.59 & 6.80 & 6.05 & 0.0941 & $-8.660 \mathrm{E}-4$ \\
1.75 & 6.05 & 8.96 & 8.38 & 6.05 & 0.0931 & $-6.980 \mathrm{E}-4$ \\
2.00 & 6.05 & 9.34 & 10.27 & 6.05 & 0.0894 & $-4.720 \mathrm{E}-4$ \\
2.25 & 6.05 & 9.73 & 12.49 & 6.05 & 0.0828 & $-1.840-4$ \\
2.50 & 6.05 & 10.14 & 15.11 & 6.05 & 0.073 & $1.760-4$ \\
\hline
\end{tabular}




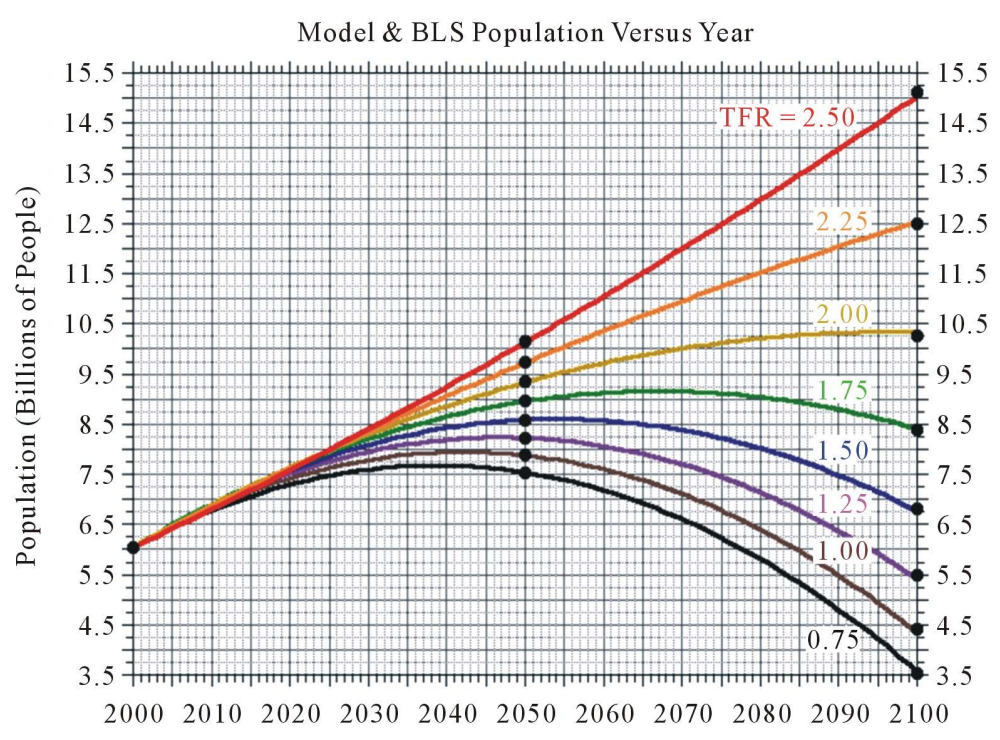

Figure 3. Population projections through the $21^{\text {st }}$ century from Equations (9) for constant TFR $(\mathrm{y})=0.75,1.00,1.25,1.50,1.75,2.00,2.25 \& 2.50 \mathrm{BPW}$, together with the BLS data shown in Table 1 (black dots).

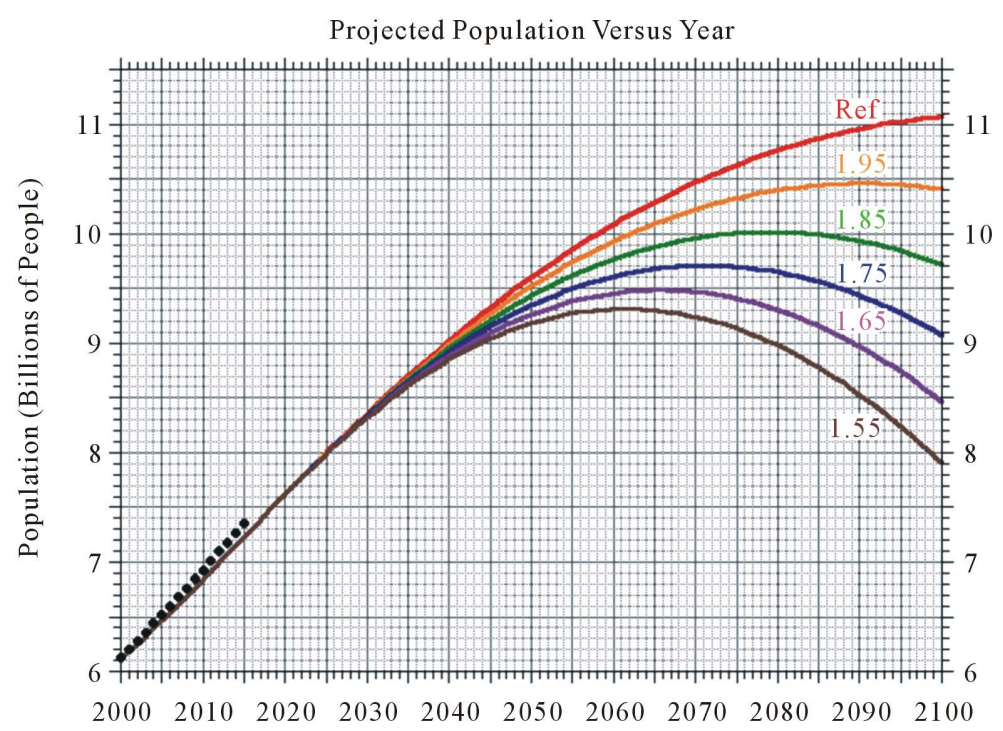

Figure 4. Population projections through the $21^{\text {st }}$ century from Equations (9) for the Reference TFR scenario (red curve) and the engineered TFR scenarios with asymptotes of 1.95 BPW (orange curve), 1.85 BPW (green curve), 1.75 BPW (blue curve), 1.65 BPW (purple curve) and 1.55 BPW (brown curve). The UN historical population data [5] are shown by the black dots.

1943. However, it should be noted that our population projections for 2004 to 2015 are less than the UN observed populations for these years. This occurs because, as shown in Figure 2, the slope of the UN observed TFR values (black dots and black curve) for the most recent 4 pentads is less negative than the slope of our Reference case (red curve) fit over the most recent 9 pentads. Accordingly, our population projections across the $21^{\text {st }}$ century may turn out to be conservative, that is, low. For the other asymptotic TFR values, the human population peaks within the $21^{\text {st }}$ century, with the size of the peak and its year of occurrence decreasing with decreasing TFR asymptote.

Figure 5 presents the 6 population projections of Figure 4 together with the population projection of the Representative Concentration Pathway 8.5 (RCP-8.5) scenario [11], which we will use in the next section to 


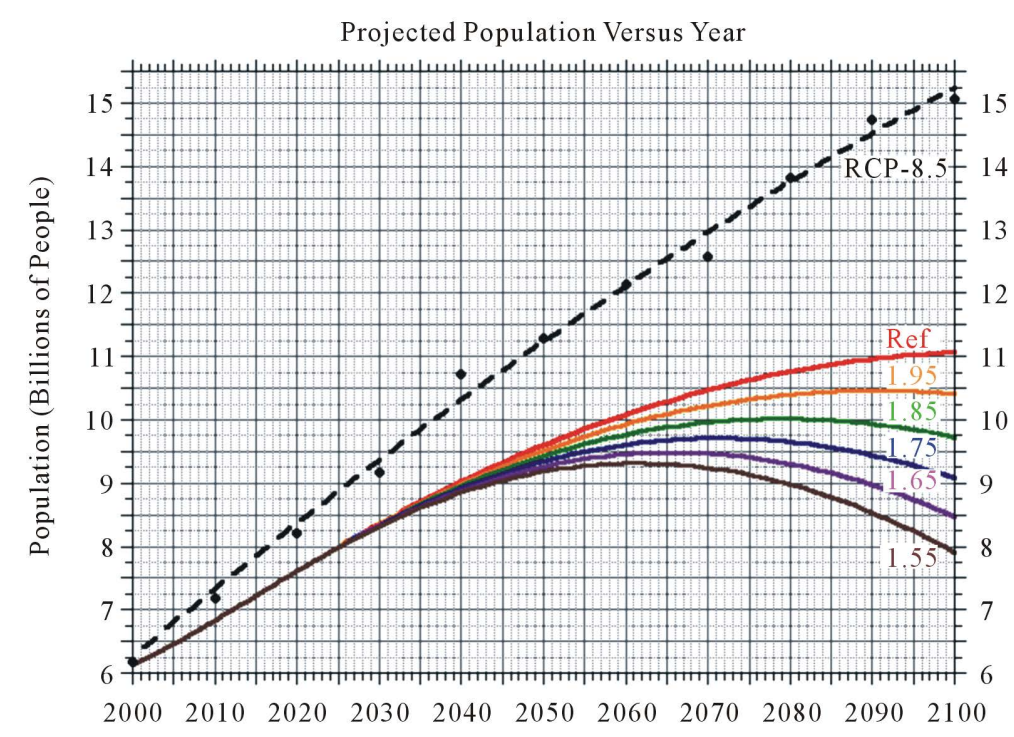

Figure 5. Population projections through the $21^{\text {st }}$ century from Equations (9) for the Reference and engineered TFR scenarios, as in Figure 4, together with the population projection of the Representative Concentration Pathway 8.5 (RCP-8.5) scenario (black dots) [11] and its fit by Equation (10, dashed black line).

craft our Reference and engineered scenarios for $\mathrm{CO}_{2}$ emissions through the $21^{\text {st }}$ century. The RCP-8.5 population scenario is identical to the A2 population scenario of the Special Report on Emissions Scenarios (SRES) [1], this as described by Riahi et al. (2011) [12]. To interpolate the RCP-8.5 population scenario to individual years we use

$$
\mathrm{P}_{\mathrm{RCP}-8.5}(\mathrm{y})=6.1038+0.11531 \mathrm{y}-0.00024552 \mathrm{y}^{2}, \quad \mathrm{y}=0, \cdots, 100,\left(\mathrm{R}^{2}=0.9953\right),
$$

\section{Emissions Projection through the $21^{\text {st }}$ Century}

The $\mathrm{CO}_{2}$ emissions for the RCP-8.5 and Fair Plan scenarios are shown in Figure 6 from our Fair Plan 8 paper [4]. Following the Kaya identity of Equation (1), we calculate the $\mathrm{CO}_{2}$ emissions for our asymptotic population trajectories of Figure 4 \& Figure 5 from

$$
E_{j}(y)=\left[P_{j}(y) / P_{R C P-8.5}(y)\right] E_{R C P-8.5}(y), \quad y=0, \cdots, 100 ; j=\operatorname{Ref}, 1.95,1.85,1.75,1.65,1.55
$$

These $\mathrm{CO}_{2}$ emissions trajectories are presented in Figure 6. For each of these scenarios, the $\mathrm{CO}_{2}$ emission peaks within the $21^{\text {st }}$ century, with the size of the peak and its year of occurrence decreasing with decreasing TFR asymptote. It should be noted that the $\mathrm{CO}_{2}$ emissions for the Reference scenario are less than the $\mathrm{CO}_{2}$ emissions for the Fair Plan scenario from 2020, when the latter starts, through 2030. This means that the Fair Plan scenario need not be initiated until 2031 and that the peak Global Warming resulting therefrom will be somewhat less than the $2^{\circ} \mathrm{C}$ target adopted by the UN Framework Convention on Climate Change "to prevent dangerous anthropogenic interference with the climate system” [13]. This is good news.

We now calculate the emissions reduction from the Reference scenario to the Fair Plan scenario achieved solely by the population reduction from the Reference scenario to the asymptotic TFR scenarios. We call this the Fulfilled Emissions Reduction (FER), given in percent by

$$
\operatorname{FER}_{\mathrm{j}}(\mathrm{y})=100 \cdot\left\{\left[\mathrm{E}_{\text {Ref }}(\mathrm{y})-\mathrm{E}_{\mathrm{j}}(\mathrm{y})\right] /\left[\mathrm{E}_{\mathrm{Ref}}(\mathrm{y})-\mathrm{E}_{\mathrm{FP}}(\mathrm{y})\right]\right\}, \mathrm{j}=1.95,1.85,1.75,1.65,1.55
$$

The $\mathrm{FER}_{\mathrm{j}}$ are presented in Figure 7 versus TFR for years 2050 and 2100.These curves may be represented by

$$
\begin{gathered}
\mathrm{FER}_{2050}(\mathrm{TFR})=57.676-16.722 \cdot \mathrm{TFR}-5.6607 \cdot \mathrm{TFR}^{2}, \quad\left(\mathrm{R}^{2}=1\right), \\
\mathrm{FER}_{2100}(\mathrm{TFR})=58.7+9.9866 \cdot \mathrm{TFR}-18.998 \cdot \mathrm{TFR}^{2}, \quad\left(\mathrm{R}^{2}=1\right),
\end{gathered}
$$


Projected $\mathrm{CO}_{2}$ Emission Versus Year

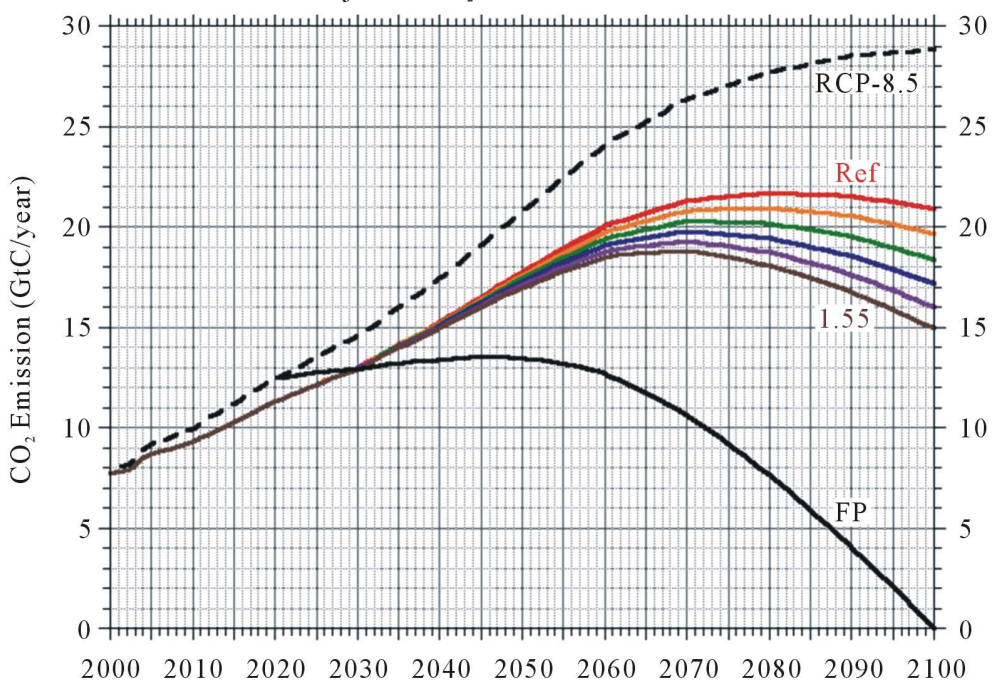

Figure 6. Projections of $\mathrm{CO}_{2}$ emissions through the $21^{\text {st }}$ century from Equation (11) for the Reference and engineered TFR scenarios, together with the $\mathrm{CO}_{2}$ emission projection of the Representative Concentration Pathway 8.5 (RCP-8.5) (dashed black line) and Fair Plan (solid black line) scenarios.

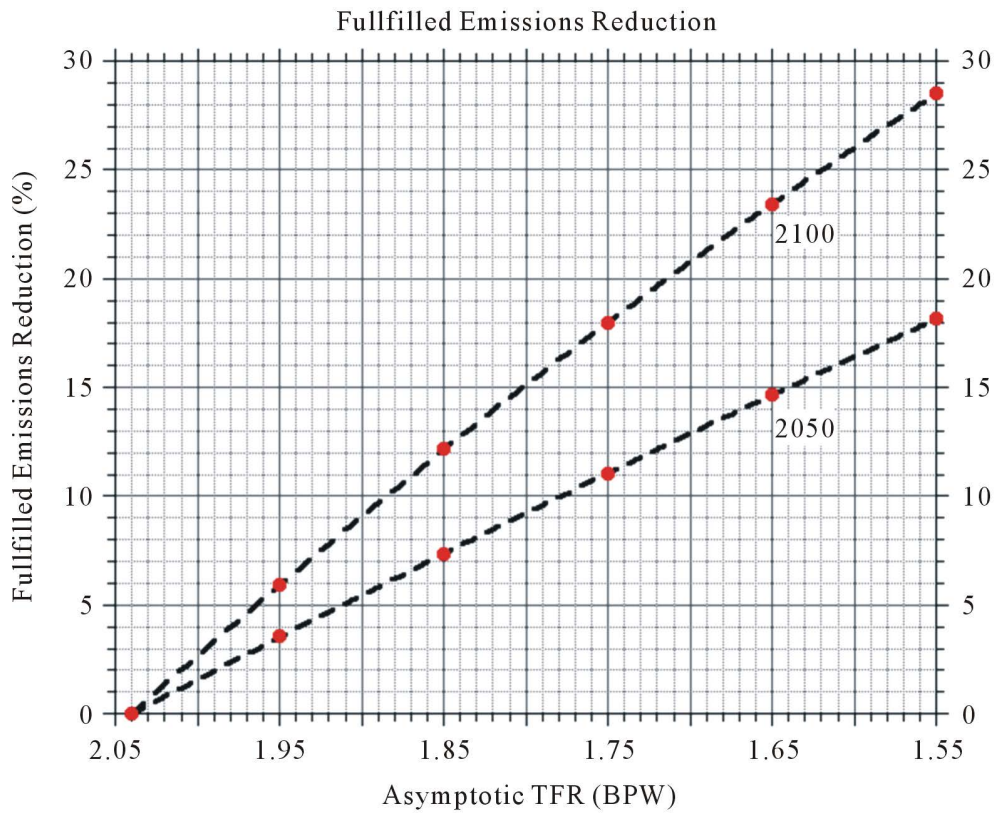

Figure 7. The Fulfilled Emissions Reduction (FER) in percent given by Equation (12) versus TFR for years 2050 and 2100 (red dots), together with their fits by Equations (13), dashed black lines.

It is seen therefrom that engineering TFR to be below the Reference value of $2.04 \mathrm{BPW}$ is an effective way of achieving a significant fulfillment of the $\mathrm{CO}_{2}$ emissions reduction required to achieve the Fair Plan $\mathrm{CO}_{2}$ emission scenario. Put another way, such TFR engineering significantly reduces the reduction in energy intensity $\mathrm{I}_{\mathrm{E}}$ and carbon intensity $\mathrm{I}_{\mathrm{C}}$ required to achieve the Fair Plan $\mathrm{CO}_{2}$ emission scenario. This too is good news.

\section{Discussion \& Conclusions}

As shown in Figure 4 \& Figure 5, the human population in our reference scenario will grow 50\% from 7.4 BP 
in 2016 to $11.1 \mathrm{BP}$ in 2100. How likely is this scenario? The truth is, no one knows, for as stated in the aphorism attributed to Neils Bohr [14] and Yogi Bera [15]: "Prediction is very difficult, particularly about the future."

The BLS authors take a rosier view of the future than our Reference scenario:

"A global move to the fertility levels seen in a number of Chinese urban centres (around 0.75) over the coming 40 years would result in a peaking of global population before 2050 and a decline to only 3.6 billion in 2100 and 150 million people by 2200 . But even the more realistic range of long term fertility levels of 1.5 - 1.75 (higher than it has been in much of Europe for the past decades) would lead to declines in global population size of 2.6 - 5.6 billion by 2200 and even 0.9 - 3.2 billion by 2300 . Therefore, even under conditions of further substantial increases in life expectancy, world population size would decline significantly if the world, in the longer run, followed the examples of Europe and East Asia.”

Well, maybe. But the 4 most-recent pentadal TFR's shown in Figure 3 suggest otherwise. Yes, these TFR's are decreasing, but they are decreasing at a decreasing rate, one which would make our Reference population projection too low, not too high. Moreover, our reference population projection may also be low because we do not consider the effect thereon of the cessation of China's one-child policy, which existed from 1980 to 2015 [16]. Accordingly, our viewpoint is that if the low TFR's described above by BLS occur autonomously, great! But, if they do not, then humanity should engineer itself to help safeguard Earth's climate.

If humanity does not, and human population increases to 11.1 BP or more in 2100, I fear that what Malthus [17] and Ehrlich [18] envisioned could very well occur, meaning that they were not wrong, but rather only that their visions were premature.

I see two possible Malthus-Ehrlich end members: 1) 1\% World and 2) Depleted-Earth World.

\subsection{1\% World}

In the " $1 \%$ World", it is Business-as-Usual, meaning that the current unequal distribution of wealth among the human inhabitants of This Island Earth [19] continues, and all current problems of human existence are perpetuated and worsened. As an example of this end member, think of the 1973 film Soylent Green [20]. This is a world in which all but "The 1\%" are starving, sleeping in stairwells and eating Soylent Green, which is recycled people. A modern version of this is the 2013 film Elysium [21]. In this vision of the future, "The 1\%" are living off Earth on a low-Earth-orbiting space station. On Elysium there is medical technology that can prolong life indefinitely for those on the space station, while for the $99 \%$ living on Earth, life is finite, short and sour.

\subsection{Depleted-Earth World}

In the "Depleted-Earth World" there is convergence to a more uniform distribution of wealth among the human inhabitants of This Island Earth, following the guidance of Pope Francis' Encyclical Letter [3], "Laudato Si': On Care for Our Common Home”. In this world there are so many people sharing the largess of Mother Earth that they deplete her natural resources. As an example of this world, think of the 1996 film Independence Day [22]. In this vision, Space Aliens come to This Island Earth because they have depleted their home planet and are traveling throughout the galaxy consuming planets as they go to sustain themselves. Earthlings cannot do this in 2100 because, even travelling at the current 35,000-miles-per-hour (56,327 kph) speed of the Voyager 1 spacecraft, which has exited the solar system, it would take 80,000 years to reach the nearest star to the Sun, Proxima Centauri, which is 25 trillion miles (40 trillion kilometers) from Earth.

Engineering human population to help safeguard Earth's climate can also help to prevent a Malthus-Ehrlich end member world in 2100 with 11.1 billion human beings. As an example, consider that humanity engineers its asymptotic TFR to be $1.75 \mathrm{BPW}$ rather than the Reference case of 2.04 BPW. Then the human population in 2100 is $9.1 \mathrm{BP}$ rather than $11.1 \mathrm{BP}$, and is decreasing into the $22^{\text {nd }}$ century (Figure 5). In such a world it should be possible to maximize the quality of human existence in a way that is sustainable, that is, it does not deplete Mother Earth's natural resources. It is for humanity to decide collectively the desired value of TFR and structure human civilization to make it so.

\section{Acknowledgements}

I thank Andy Revkin for emailing me the URL to the BLS paper. 


\section{References}

[1] Nakicenovic, N., Alcamo, J., Davis, G., Vries de, B., Fenhann, J., Gaffin, S., Gregory, K., Grübler, A., Jung, T.Y., Kram, T., Rovere, E.L.L., Michaelis, L., Mori, S., Morita, T., Pepper, W., Pitcher, H., Price, L., Riahi, K., Roehrl, A., Rogner, H.-H., Sankovski, A., Schlesinger, M., Shukla, P., Smith, S., Swart, R., van Rooijen, S., Victor, N. and Dadi, Z. (2000) Special Report on Emissions Scenarios, a Special Report of the Intergovernmental Panel on Climate Change. Cambridge University Press, Cambridge, 570 p. http://www.grida.no/climate/ipcc/emission/index.htm

[2] Hoffert, M.I., Caldeira, K., Jain, A.K., Haites, E.F., Harvey, L.D.D., Potter, S.D., Schlesinger, M.E., Schneider, S.H., Watts, R.G., Wigley, T.M.L. and Wuebbles, D.J. (1998) Energy Implications of Future Stabilization of Atmospheric $\mathrm{CO}_{2}$ Content. Nature, 395, 881-884. http://www.nature.com/nature/journal/v395/n6705/abs/395881a0.html http://dx.doi.org/10.1038/27638

[3] Francis, P. and Si’, L. (2015) (Encyclical Letter): On Care for Our Common Home. Vatican Press, 184 p. http://w2.vatican.va/content/francesco/en/encyclicals/documents/papa-francesco_20150524_enciclica-laudato-si.pdf

[4] Schlesinger, M.E., Ring, M. and Cross, E. (2016) Fair Plan 8: Earth’s Future Climate-Pope Francis’ Population Mistake. Atmospheric and Climate Sciences, 6, 103-111. http://www.scirp.org/journal/PaperInformation.aspx?PaperID=63056

[5] United Nations, Department of Economic and Social Affairs, Population Division (2015) World Population Prospects: The 2015 Revision, DVD Edition. http://esa.un.org/unpd/wpp/Download/Standard/Population/

[6] United Nations, Department of Economic and Social Affairs, Population Division (2015). World Population Prospects: The 2015 Revision, DVD Edition. http://esa.un.org/unpd/wpp/Download/Standard/Fertility/

[7] Historical Statistics of the World Economy: 1-2008 AD, (Copyright Angus Maddison). XLS File Downloadable from Statistics on World Population, GDP and Per Capita.

https://www.google.com/webhp?sourceid=chrome-instant\&ion=1\&espv=2\&ie=UTF-8\#q=world+population+historical $\underline{+ \text { data }+x l s}$

[8] http://www.worldometers.info/world-population/

[9] Basten, S., Lutz, W. and Scherbov, S. (2013) Very Long Range Global Population Scenarios to 2300 and the Implications of Sustained Low Fertility. Demographic Research, 28, 1145-1166. http://dx.doi.org/10.4054/DemRes.2013.28.39

[10] United Nations, Department of Economic and Social Affairs, Population Division (2015). World Population Prospects: The 2015 Revision, Key Findings and Advance Tables. Working Paper No. ESA/P/WP.241.

[11] Meinshausen, M., Smith, S.J., Calvin, K.V., Daniel, J.S., Kainuma, M., Lamarque, J.-F., Matsumoto, K., Montzka, S.A., Raper, S.C.B., Riahi, K., Thomson, A.M., Velders, G.J.M. and van Vuuren, D. (2011) The RCP Greenhouse Gas Concentrations and their Extension from 1765 to 2500. Climatic Change. http://edoc.gfz-potsdam.de/pik/get/5095/0/0ce498a63b150282a29b729de9615698/5095.pdf

[12] Riahi, K., Rao, S., Krey, V., Cho, C., Chirkov, V., Fischer, G., Kindermann, G., Nakicenovic, N. and Rafaj, P. (2011) RCP 8.5-A Scenario of Comparatively High Greenhouse Gas Emissions. Climatic Change, 109, 33-57. http://dx.doi.org/10.1007/s10584-011-0149-y

[13] United Nations, Report of the Conference of the Parties on Its Sixteenth Session (2010) Cancun, Mexico, 31 p. http://unfccc.int/resource/docs/2010/cop16/eng/07a01.pdf\#page=2

[14] https://en.wikiquote.org/wiki/Niels Bohr

[15] http://www.goodreads.com/quotes/261863-it-s-tough-to-make-predictions-especially-about-the-future

[16] Pletcher, K. (2015) One-Child Policy: Chinese Government Program. Encyclopedia Britannica. http://www.britannica.com/topic/one-child-policy

[17] Malthus, T. (1798) An Essay on the Principle of Population as It Affects the Future Improvement of Society with Remarks on the Speculations of Mr. Godwin, M. Condorcet and Other Writers, London, Printed for J. Johnson, in St. Paul's Church-Yard, 134 p.

[18] Ehrlich, P.R. (1968) The Population Bomb, Sierra Club/Ballantine Books. 201 p.

[19] http://www.imdb.com/title/tt0047577/

[20] http://www.imdb.com/title/tt0070723/

[21] http://www.imdb.com/title/tt1535108/

[22] http://www.imdb.com/title/tt0116629/ 